

\section{FELIPE GONZÁLEZ VICÉN (1908-1991)}

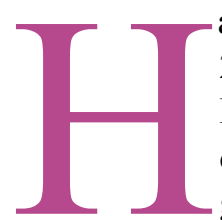
a muerto, nuestro viejo maestro y amigo, a los ochenta y tres años, el pasado 22 de febrero en La Laguna (Tenerife), de cuya Universidad era catedrático de Filosofía del Derecho desde 1946. Fue enviado allí (¡afortunadas islas!) como destino forzoso y que de hecho resultó inamovible una vez que después de la guerra (civil y mundial) logró ser readmitido en la docencia tras su destitución de la Universidad de Sevilla en 1936. En medio, en esos tan terribles y difíciles años, tuvo que optar como tantos otros por la salida traumática de España recorriendo media Europa como emigrado político para encontrar, al fin, acogida en Alemania bajo la protección de la familia de su mujer Ruth Dörner, siempre su gran autodefensa allí y aquí, accediendo incluso a un puesto de trabajo que le permitió subsistir hasta la conclusión de su emigración.

Felipe González Vicén había nacido en Santander, creo que de familia vallisoletana, en 1908; desde el principio, muy destacado e inteligente estudiante, licenciado en Derecho, fue después pensionado por la Junta de Ampliación de Estudios en Italia, Inglaterra y Alemania, logrando, a los veintisiete años, la cátedra de Filosofía del Derecho de la Universidad de Sevilla en 1935. Su primer libro, Teoría de la revolución. Sistema e historia, había aparecido en 1932 publicado por la Universidad de Valladolid, donde aquél había cursado sus estudios e iniciaba por entonces su preparación como docente. Toda su posterior vida académica habría de transcurrir invariable desde 1946 en la Universidad de La Laguna, donde se jubiló en 1978, aunque con frecuentes visitas de trabajo a centros de investigación de no pocas universidades europeas, habiendo ejercido entre ellas durante varios años como profesor visitante en la Universidad de Heidelberg. 
De su reincorporación a España habría pronto de quedar permanente y muy importante selectiva señal al corresponderle pronunciar la solemne lección inaugural del curso académico 1946-47 en la Universidad de La Laguna, para la cual González Vicén eligió como muy oportuno tema La filosofía del Estado en Kant. Aunque dicha lección fue después publicada, en 1952, su difusión resultó ser escasísima y desde luego que de muy rara lectura y utilización por los historiadores de las ideas políticas o los iusfilósofos españoles de la época: a pesar de su valía y de ser una de las pocas monografías publicadas entre nosotros sobre el pensamiento jurídico y político de Kant, apenas se la cita ni se la conoce en todo este tiempo; Manuel Atienza -Infatigable indagador- hablaba de ella en 1981, pero igual podría haberse dicho mucho antes, como de «un trabajo prácticamente inencontrable» ${ }^{1}$.

Esta densa y documentada indagación sobre la filosofía del Estado en Kant es, en verdad, un estudio sistemático, aunque sintetizado, sobre la entera filosofía práctica de aquél (ética, jurídica y política), teniendo en cuenta «el hecho fundamental -decía allí el profesor González Vicén- de que toda la reflexión ética de Kant, desde las categorías básicas de la filosofía moral, pasando por el campo del Derecho y de la "ética externa", culmina en la idea del Estado y recibe en ella su sentido último». Nada de extrañar que -dando apoyo además a las calificaciones que en la época se hacen de aquél como neohegeliano- él mismo defina que su propia concepción y su «principio metódico es la consideración de la filosofía crítica, no como un

${ }^{1}$ Lamentaba éste, por tanto y con plena razón, que dicho trabajo no hubiera sido incluido en la recopilación de los escritos de González Vicén, Estudios de filosofía del Derecho, que como libro-homenaje había sido editado por la Facultad de Derecho de dicha Universidad canaria con ocasión de su jubilación en 1978 (Manuel Atienza, «La filosofía del Derecho de Felipe González Vicén», Revista de la Facultad de Derecho de la Universidad Complutense de Madrid, núm. 62, 1981, pág. 68). Algo más adelante logré al fin que se republicase aquel trabajo de 1952 sobre Kant incluyéndolo en la nueva recopilación que solicité al prof. González Vicén para la colección «El Derecho y el Estado» que yo entonces dirigía en la Editorial Fernando Torres, de Valencia: allí salió en efecto, en 1984, como capítulo primero de su obra De Kant a Marx (Estudios de historia de las ideas), edición por la cual se cita aquí. Estas dos recopilaciones, más su mencionada, primeriza, obra de 1932 sobre teoría de la revolución, es lo que ha quedado publicado de González Vicén en forma propiamente de libro: más o menos dispersos (algunos -los más antiguos, publicados en Alemania- de no fácil localización) tenemos, no obstante, otros diferentes artículos y estudios, todos de alta calidad, que componen junto a las traducciones de importantes obras- el conjunto de su muy rigurosa, muy cuidada y erudita labor intelectual. 
sistema en el sentido meramente formal del neokantismo, sino como un sistema en el sentido sustantivo y profundamente histórico de la tradición hegeliana» ${ }^{2}$. Ese sentido «profundamente histórico», a confrontar con la que sea buena «tradición hegeliana», es el que guía también la exposición y crítica que se contiene en su extenso, y éste ya mucho más difundido trabajo, aparecido en 1950, sobre El positivismo en la filosofía del derecho contemporánea, así como en su estudio preliminar, de 1951, a la traducción española de la obra de John Austin «Sobre la utilidad del estudio de la Jurisprudencia» ${ }^{3}$.

Estos fueron los trabajos -de crítica al iusnaturalismo y al formalismo, de defensa de un cierto, a veces no muy bien definido, historicismo- a través de los cuales se produce en esos años la reincorporación del profesor González Vicén a la docencia y a la investigación en la Universidad española. Estos fueron, a su vez, los trabajos que sirvieron como incentivo muy poco después para el acercamiento y el conocimiento de su obra a los que por entonces, en otras latitudes (yo concretamente en Salamanca con los profesores Joaquín Ruiz Giménez y Enrique Tierno Galván), nos iniciábamos en el estudio de la filosofía jurídica, filosofía ésta que de siempre se nos aparecía como conectada en sus planteamientos de fondo con la ética y la filosofía política.

Querría resaltar aquí, en esa perspectiva, la línea de continuidad que, orientada desde la prevalencia del individuo, de la

${ }^{2}$ De Kant a Marx, cit., págs. 14 y 15. Legaz Lacambra en la información complementaria que sobre los iusfilósofos españoles e hispanoamericanos insertaba en la versión en castellano de la Filosofía del Derecho de Giorgio del Vecchio (Barcelona, Bosch, 6. ${ }^{\text {a }}$ ed., 1953, pág. 275), al igual que en otros escritos suyos de esos mismos años a que luego -nota 14- me referiré, califica la filosofía de González Vicén como «de inspiración neohegeliana». Manuel Atienza (ob. cit., pág. 68) tras referirse a esas anteriores conexiones neohegelianas de aquél -estudiadas también en la tesis de licenciatura de Juan Carlos Bayón, Alternativas al Derecho natural escolástico en la filosofía jurídica española del primer tercio del siglo XX, Universidad Autónoma, Madrid, 1980)- concluye con buen criterio: «Quizá quepa decir que en su evolución posterior (posterior a 1937) González Vicén se va desprendiendo del idealismo de Hegel, pero conserva -dice aquel- un rastro de Hegel en su decidido historicismo». Cuestión debatida, en efecto y a estudiar con detalle, es si ese «historicismo» (más personalista que objetivista) le acerca después no tanto a Hegel como a un cierto existencialismo, al que también aludirá aunque invirtiendo ese orden cronológico el propio Legaz.

${ }^{3}$ Ambos trabajos se publicaron en el marco del «Instituto de Estudios Políticos», de Madrid: los artículos sobre el positivismo en la Revista de Estudios Políticos, núm. 51 (mayo-junio de 1950) y núm. 52 (julio-agosto de 1950); el libro de Austin en la colección Civitas, reeditado por su continuador «Centro de Estudios Constitucionales», en 1981. 
persona humana individual, de los valores de libertad y de autonomía de la voluntad, recorre precisamente la filosofía ética, jurídica y política del profesor González Vicén en aquellos tan complicados y conflictivos años de preguerra, guerra e inmediata postguerra (también siempre después), años a que ahora me estoy preferentemente refiriendo, y ello -esa línea de continuidad- a pesar de los difíciles avatares personales y las grandes conmociones históricas de la época. En esos tres decenios exactos que van de la publicación, en 1932, de su Teoría de la revolución a, en 1952, La filosofía del Estado en Kant permanece, creo, con toda claridad, con cambios sólo secundarios, esa común defensa de los valores del individuo y de la libertad: entre estas dos obras hay, desde luego, otros varios trabajos de diferente temática (sobre Unamuno, Donoso Cortés, la Escuela de Derecho Natural, la Filosofía del Derecho española contemporánea) que, por lo que conozco, no alteran para nada aquella línea fundamental.

Así, en el primero de aquellos libros, el de 1932, el joven González Vicén (veinticuatro años y en los albores de la segunda república española), tras asumir «la evolución racionalista e individualista llevada a cabo desde el Renacimiento», viene incluso a remarcar -con, sin duda, los mayores específicos aplausos de algún sector de sus admiradores de hoy, más propensos al segundo que al primero de los términos de esa evolución- que «en nuestros días el individualismo es también -dice aquél-una de las más fuertes realidades». Señala en todo caso con muy válida determinación, con la que concuerdo, que «el Estado y el Derecho deben hallarse en servicio del individuo»; y continúa consecuentemente: «El Derecho y el Estado tienen por lo tanto una dignidad ética pero no sustantiva e inmanente sino derivada del valor moral que representan para los sujetos jurídicos individuales; no poseen sino un valor ético-individual derivado, no propio». Su conclusión es, pues, clara y diáfana en la vía de la defensa de la persona individual -en la cual, subrayo por mi parte, habría que introducir coherentes exigencias de carácter socialen tiempos, recuérdese, de frecuentes entificaciones estatales, metafísicas, transpersonalistas y totalitarias: «El Derecho y el Estado -escribía González Vicén- son, pues, medios al servicio de los valores individuales. Su fin estricto consiste en crear un ambiente propicio al logro más completo y fecundo de éstos. Es decir -puntualiza aquél en ese libro que, no se olvide, trata del análisis del derecho de resistencia y de las hipotéticas razones para la legitimidad de una revolución-, que de los predicados de la personalidad humana puede emanar una pretensión frente 
a los poderes públicos cuando éstos desconozcan su rango y dignidad $»^{4}$.

Treinta años después (1952, González Vicén ya en su madurez, en la España de Franco, con un régimen confesional y de ortodoxias doctrinales como sustento de una dictadura política que empieza vergonzantemente a querer disfrazarse de «democracia orgánica») escribirá, tomando a Kant como pretexto: «El cometido del Estado no es conseguirnos por la fuerza la felicidad sino sólo "el mantenimiento de la forma puramente legal de una sociedad civil”. Si se piensa, por ejemplo -añade (im)pertinentemente González Vicén-, en el ejercicio de la religión o en la labor científica que cada uno puede desarrollar, el deber del Estado no es intervenir señalando en cada uno de estos terrenos lo que es cierto y lo que, según su parecer, conduce mejor a la felicidad individual o colectiva, sino exclusivamente cuidar de que cada ciudadano pueda desarrollar su actividad libremente dentro de los límites señalados por el Derecho, y sin que nadie pueda perturbar la esfera garantizada por el orden Jurídico.» Y no deja otra vez de recordar, tras insistir en la conexión entre Derecho y libertad: «También aquí el fin esencial es el establecimiento de un orden de la máxima libertad humana según leyes.» En oposición radical al despotismo ilustrado, «el Estado en el sentido kantiano presupone siempre, en cambio, un orden natural surgido de la libre determinación ética de los individuos». Concluirá, pues, González Vicén: «Este orden así dotado de certeza es el fin último de la historia, lo que la presta sentido y la hace racionalmente inteligible. No la felicidad, ni ningún otro objetivo que se halle en la naturaleza -remarcará aquél-, sino sólo un objetivo que el hombre se propone a sí mismo por la razón y para la consecución del cual la naturaleza le es sólo medio, no fin en sí misma. La condición formal de esta libre determinación es el Estado como condición del Derecho, el cual, por eso, se eleva a fin último en el desenvolvimiento de la humanidad: es decir -termina González Vicén con las propias palabras de Kant en la Crítica del juicio- "aquella constitución en las relaciones entre los hombres, por la cual la violación de la libertad recíproca se enfrenta con un poder legal dentro de una totalidad que se llama sociedad civil"»"

${ }^{4}$ Teoría de la revolución, cit., págs. 146, 148 y 149. Para que sea «lícito reaccionar violentamente contra los poderes públicos», González Vicén exige que «los atentados contra los postulados sustanciales de la personalidad se verifiquen -dice- de un modo general y como sistema».

${ }^{5}$ La filosofía del Estado en Kant, cit., págs. 88, 90 y 91. Véase en relación con ello y como valioso análisis de ese libro de González Vicén, el trabajo de 
En esos términos, como viejo y auténtico liberal, en la estela del mejor liberalismo ético de nuestro país (más kantiano-hegeliano que krauso-institucionalista, dentro de esa común herencia del idealismo alemán), hablaba González Vicén en la España de 1952: y ello, desde luego, no pierde valor alguno por el hecho indudable de que su discurso de docto y erudito profesor fuese casi exclusivamente filosófico, o de temas de historia de las ideas jurídicas europeas, siempre con elevado nivel científico y de abstracción, sin aparente excesiva incidencia concreta sobre las situaciones reales, políticas y sociales, de aquellos tan difíciles momentos de nuestra historia contemporánea. Fueron largos tiempos, más de veinte años, de fuerte trabajo casi en solitario, de muy serio estudio y de sosegadas investigaciones sobre fuentes originales tanto en su magnífica biblioteca particular, muy próxima por lo demás su vivienda a la Facultad de Derecho en La Laguna, como en bibliotecas de otras Universidades europeas, con el resultado exterior de muy escasas pero, como siempre, muy cuidadas publicaciones (sin olvidar nunca sus numerosas, fieles e importantes traducciones del alemán muy fundamentalmente): años también de relativo aislamiento en las islas los que transcurren hasta ya las últimas fases del anterior régimen, casi entrada la década de los setenta. Fue en aquel largo tiempo cuando tomamos mayor contacto con él, primero científico a través de las lecturas, luego personal y afectivo, algunos de los que entonces ejercíamos de jóvenes iusfilósofos: en sus trabajos encontrábamos a la vez que nuevos conocimientos y nuevas perspectivas de validez teórica y científica más general, también materiales sumamente certeros para algo que a algunos también nos interesaba como era la crítica intelectual a los presupuestos jurídico-políticos del franquismo ${ }^{6}$.

Tendremos que escribir con más detenimiento y siempre con

José Luis Colomer Martín-Calero, «De Kant a Marx: Ilustración, Praxis y Derecho», Sistema, núm. 70, enero de 1986, págs. 125-134.

${ }^{6}$ En los veinticinco años que van desde aquel lejano 1952 y hasta 1977 , ya en la transición hacia la democracia, son -como digo- pocos pero excelentes los artículos y trabajos que publica González Vicén; seis, creo, en total, cinco de ellos recogidos después, en 1978, en la mencionada recopilación de sus Estudios, donde podrán encontrarse más datos sobre las revistas (Anuario de Filosofía del Derecho, preferentemente) y obras colectivas donde aquéllos aparecieron; recuerdo aquí solamente sus títulos y fechas: Sobre los orígenes y supuestos del formalismo en el pensamiento jurídico contemporáneo (1961); Del Derecho natural al positivismo jurídico (1967); Sobre el positivismo jurídico (1967); La Filosofía del Derecho como concepto histórico (1969); La teoría del Derecho y el problema del método jurídico en Otto von Gierke (197 1); La filosofía del Derecho de Ludwig Krutpp (1977). 
gratitud sobre lo mucho que debemos al profesor González Vicén una gran parte de quienes, de nuestra generación, nos hemos dedicado a la investigación y a la docencia universitaria en estas áreas (yo, desde luego, me he honrado en reconocerlo así desde mi Sociología y Filosofía del Derecho, de 1971), tanto en apoyos prácticos en difíciles momento del viejo pasado como en aportaciones suyas de carácter teórico y de historia de las ideas que constituyen referencias ineludibles, también para el debate, la crítica y la discrepancia, en el panorama de la filosofía jurídica, ética y política de nuestros días. Auguro, en este sentido, que una buena investigación sobre su personalidad y sobre su obra, distante, dispersa, culta, compleja, sugerente, poco difundida y estudiada, daría lugar sin ningún género de dudas a, por ejemplo, una necesaria y muy interesante tesis doctoral a la que sigo animando desde aquí (la verdad es que ya no con excesiva esperanza) a alguno de nuestros jóvenes graduados. Ojalá tuviera yo mismo edad y tiempo para meterme a ello. Así pues, el objetivo de estas líneas mías era, y es, aquí doble: por un lado, sobre todo, el de dejar explícita constancia de este entrañable recuerdo de nuestro maestro y amigo, ilustrando sucinta -pero espero que no inexactamente- sobre su vida y sobre sus trabajos; pero, por otro, y consciente precisamente de las insuficiencias de ellas, de estas líneas, el de seguir instando, como digo, a algún joven, o viejo investigador para que -no se me ofendan-, permitiendo descansar durante algunos meses la enésima exégesis, la golosa glosa, sobre el último epígono, analítico o no, de la metaética o de la jurisprudencia estadounidense, se decida a conceder alguna pequeña pero buena atención, en el solar patrio, a la filosofía jurídica, ética y política del gran don Felipe González Vicén?.

De todos modos, algunas cosas ya hemos dicho y estamos diciendo sobre él los seniors, los «viejos» si se prefiere, además de en obras más académicas y/o científicas bien conocidas, también en artículos periodísticos -por ejemplo, Gregorio Peces-Barba, Javier Muguerza o yo mismo- con ocasión posterior a su jubilación universitaria en 1978: González Vicén, una crítica historicista de las ideologías jurídicas del franquismo fue el rótulo que, arrancando de mi ya mencionado libro, propuse yo entonces como hispánica síntesis, en clave filosófico-política, de su pensamiento ${ }^{8}$. Las específicas ideologías a las que González Vicén

${ }^{7}$ Ya era esa también la intención de mi artículo sobre él publicado en el periódico El Sol, de Madrid, el 29 de marzo de 1991, algunas semanas después de su muerte y del cual estas páginas, que lo subsumen, no son sino una muy esquemática y sectorial prolongación y ampliación.

${ }^{8} \mathrm{Y}$ ese era efectivamente el título que yo le puse a mi artículo pero el 
se opuso siempre, y que -en versiones las más simplistas y reaccionarias- precisamente coincidían con las que en orden cronológico y axiológico pretendieron otorgar legitimidad al régimen dictatorial del general, eran en definitiva y en sustancia las dos siguientes: por un lado, el iusnaturalismo integrista, autoritario, eclesiástico-religioso, católico-tradicional, de la mayor parte de los filósofos del Derecho en la España de la época (en seguida con algunas significativas fisuras y discrepancias en su interior, iusnaturalistas que después hicieron no poco por los derechos humanos y naturales); por otro, el formalismo de los juristas que de hecho sacralizaban, no todos ni los mejores, la ilegítima legalidad de aquel Estado antidemocrático y antiliberal bajo la cobertura de un aparente neutralismo o del silencio abstencionista de los técnicos, de los tecnócratas que, por los años cincuenta y sesenta, vinieron a suceder a los teólogos a veces doblándose sin más en ellos.

Todavía no está hecha una historia crítica del pensamiento jurídico español bajo el franquismo, tanto del que -en mayor o menor medida- apoyó al régimen totalitario/ autoritario como del que -de un modo u otro- impulsó a la oposición democrática contra aquél ${ }^{9}$. Por lo que se refiere a la ideología legitimadora, a la filosofía oficial, podría decirse que ésta vino pronto y con frecuencia a concretarse en un esquizoide producto, resultado de la amalgama del más sublime iusnaturalismo, para las grandes invocaciones de principios en los momentos solemnes,

duende (en este caso quizá sería mejor decir el fantasma) de las prensas además de abreviar y cortar el contenido del trabajo por donde quiso (sin duda que por «razones de espacio», acabó rotulándolo absurdamente, y sin contar para nada conmigo en ninguna de esas operaciones traumáticas, como la «crítica jurídica del franquismo»; y así se cita, claro está, por colegas y estudiosos del tema; quien lo leyere podrá, no obstante, observar que al reducir aquél sin orden ni concierto quedó, entre lo no suprimido, la referencia (¡menos mal!) a la filosofía de González Vicén «que aquí se ha calificado, en el título del artículo» -podía leerse pero sin apoyatura textual alguna- de «historicista»: en ese mismo número y página de El País ( 6 de julio de 1980) apareció la muy divertida y, a la vez, muy sugerente semblanza de don Felipe definido con acierto por Javier Muguerza como Un solitario «don» de La Laguna; el artículo de Gregorio Peces-Barba, Homenaje al profesor González Vicén, se publicó antes, en el mismo periódico, el 7 de junio de 1980.

${ }^{9}$ Se ha empezado, y bien, por la órbita judicial: así, los libros de Juan Cano Bueso, $L a$ política judicial del régimen de Franco, 1936-1945 (Prólogo de José Cazorla, Madrid, Ministerio de Justicia. 1985), de Francisco J. Bastida, Jueces y franquismo. El pensamiento político del Tribunal Supremo en la dictadura (prólogo de J. A. González Casanova, Barcelona, Ariel, 1986) y de Carlos Pérez Ruiz, La argumentación moral del Tribunal Supremo (1940-1975), prólogo de Antonio E. Pérez-Luño, Madrid, Tecnos, 1987. 
con el más estrecho formalismo, para la práctica diaria con el Derecho. Si uno -el iusnaturalismo- era más metafísico y teológico, otro -el formalismo- era más eficiente y seguro; los dos juntos y cada cual desde su banda, unos con grandes palabras, otros con grandes silencios, cada cual por su camino pero juntos al final bajo el general, se confabulaban para hacer creer que en tal situación la ley y la justicia coincidían sin más entre sí, que lo que de hecho «era» (en las leyes de las Cortes franquistas o en los decretos y actos del gobierno dictatorial) coincidía en esencia con lo que «debía ser»: y éstos, los grandes valores, era algo que se imponía a su vez de manera monolítica y dogmática, es decir, sin participación democrática de ningún tipo, desde las más altas jerarquías políticas y eclesiásticas del país ${ }^{10}$.

Desde luego que la crítica de González Vicén a esas dos tan consolidadas teorías, e ideologías, como son el iusnaturalismo y el formalismo, tenía mucho, muchísimo, más alcance que el de esas sus concretas determinaciones, teológicas y tecnocráticas, en el contexto hispánico de la época; sus críticas iban también, e incluso puede decirse que de manera más abierta y expresa, contra el iusnaturalismo racionalista, precisamente por tratar de imponer a la conciencia individual normas, «soluciones», pretendidamente universales, y asimismo contra el formalismo de la escuela analítica de, por ejemplo, un Austin, inventor -acusaba Vicén- de «una Ciencia del Derecho sin Derecho». Pero aquéllas -las ideologías hispánicas- tampoco se libraban de sus fuertes objeciones a éstas -a las ideologías europeas-, disociación

${ }^{10}$ Por lo que se refiere al pensamiento crítico y de oposición en la estricta filosofía jurídica española de esos tiempos, puede verse -para algunas parcelas de él- Francesca Puigpelat, Sobre la filosofía jurídica marxista española, «Crítica Jurídica», Universidad Autónoma de Puebla (México), núm. 5. 1987, págs. 27-42. Y con materiales y datos para ambos sectores, José F. Lorca Navarrete, $L a$ filosofía jurídica española contemporánea, apéndice de su traducción al vol. III de la obra de Guido Fassó, Historia de la Filosofía del Derecho, Madrid, Pirámide, 1981, págs. 289-385; también, Modesto Saavedra, Bibliografía de la Filosofía del Derecho en España (1961-1971), «Anales de la cátedra Francisco Suárez,», Universidad de Granada, núm. 12, fascículo, V. 1972. págs. 161-200; y asimismo, muy especialmente, los artículos de Nicolás María López Calera, La Cátedra «Francisco Suárez» de la Universidad de Granada (1939-1985) y de Juan José Gil Cremades. Filosofía del Derecho en España (1960-1985), ambos en «Anales de la Cátedra Francisco Suárez», Universidad de Granada, núm. 25, 1985, págs. 1-11 y págs. 225-243, respectivamente. Para un posible entronque y confrontación de todo ello con otros aspectos más generales de nuestra vida intelectual, reenviaría a mi libro Pensamiento español en la era de Franco (1939-1975), Madrid, Ed. Tecnos, 3. ${ }^{\text {e ed- }} 1983$. con amplia bibliografía más o menos pertinente también para estos temas de filosofía ética, jurídica y política. 
que se daba, por el contrario, entre nuestros iusnaturalistas teológicos, que sólo repudiaban absolutamente el iusnaturalismo racionalista, así como entre no pocos juristas formalistas que, con mil subterfugios, se resistían a la identificación con sus homólogos europeos, demócratas y liberales en política, más relativistas y pluralistas en ética.

González Vicén ejercía esas críticas (teóricas, científicas, no directamente políticas) desde una posición que -como ya he señalado- yo mismo he calificado, aunque sin propósitos definitorios rígidos y estrictos, como de historicista: pero de un historicismo que, vistas también sus críticas a Savigny y -de acuerdo con Marx- al «quietismo reaccionario de la Escuela histórica» ${ }^{11}$ venía de siempre vinculado con un positivismo no legalista (es decir, diverso del que él criticaba a las reducciones formalistas), con actitudes más bien de carácter sociológico o realista, sin agotarse tampoco, no obstante, en las meras determinaciones fácticas de la legalidad o la legitimidad. Complejidad, pues, como se ve, de ese historicismo no reduccionista de González Vicén: el Derecho viene así entendido por él, con algún recelo antinormativista del cual discrepo, como ordenamiento concreto de la vida real (¿quién es y debe ser el principal generador de tal organización?), como producto de un grupo humano concreto en un momento histórico concreto.

Desde estas coordenadas analiza y profundiza después Manuel Atienza esa filosofía jurídica del profesor González Vicén en el trabajo más sistemático y extenso, veinte apretadas páginas con muchas sugerencias interesantes, de que hasta la fecha disponemos sobre el catedrático de La Laguna. Allí también destaca Atienza ese historicismo como criterio válido para aquel respecto al problema de la legitimidad, el problema de la justicia, de la moral y (¡arduo debate!) de la misma obligación o no obligación ética de obedecer al Derecho, actitud esta última en la que -como es bien sabido- se sitúa González Vicén. Para toda esta polémica, en la que no puedo ahora volver a entrar, bueno será leer la obra de Eusebio Fernández con quien, no sin discrepancias posteriores, en este punto yo concuerdo más: razones éticas para desobedecer pero también posibles razones éticas para obedecer ${ }^{12}$.

${ }^{11}$ La crítica de Marx a la Escuela Histórica, «Sistema», núm. 43-44, septiembre de 1981; incluido después en su recopilación De Kant a Marx, cit., págs. 175-229 y aquí en concreto págs. 192 y 195.

${ }^{12}$ Eusebio Fernández García, La obediencia al Derecho, Madrid, Civitas, 1987: allí podrá encontrarse bibliografía y otras informaciones sobre este debate que tiene enfrentados a no pocos éticos y iusfilósofos españoles actuales (cfr. 
En cualquier caso, de lo que yo querría dejar ahora directo y personal testimonio en estas páginas es en que todo esto de obedecer o desobedecer no era «pura teoría» para el profesor González Vicén: tengo, desde luego, pruebas absolutamente fehacientes de que desobedeció no sé si leyes fundamentales de la democracia orgánica (su solitario y orgulloso distanciamiento le hacía ya inmune a los mezquinos reclamos de ésta) pero si, desde luego, que se enfrentó y supo decir no a informales y amenazantes órdenes ministeriales, y de otros altos rangos e influencias, por considerarlas inicuas, injustas, ilegítimas, inmorales e, incluso, ilegales sin más, en circunstancias muy concretas, algunas que me afectaban entonces muy de cerca y en las que siempre contó aquél con la activa colaboración y solidaridad de los profesores José Delgado Pinto y Nicolás María López Calera. En su ya mencionado artículo de homenaje a aquel, Gregorio Peces-Barba se ha referido expresa y generosamente a algunas de aquellas luchas y peripecias de nuestras comunes biografías universitarias para señalar, con buena justificación, que «quizá lo que más he admirado y admiro del profesor González Vicén es -dice- su rectitud moral y su sentido del cumplimiento del deber por el puro estímulo del deber». Reacio, creo, a universalismos uniformizadores, así, como exigente deber personal, es como se lo tomó él, coincidiendo felizmente con otros en aquella referida ocasión ${ }^{13}$.

especialmente sobre ello, págs. 91-115). Después, también, Marina Gascón Abellán, Obediencia al Derecho y objeción de conciencia, Madrid, Centro de Estudios Constitucionales, 1990. Aunque, como digo, no son, en modo alguno. estas notas lugar oportuno para volver sobre todo ello, y, aunque intuyo las respuestas a mis alegaciones, no querría, sin embargo, dejar sin observar como en su ya citado estudio sobre La filosofía del Estado en Kant (1952), González Vicén tras insistir -¿hablando sólo de éste»- en que «el Derecho queda revestido de un valor ético absoluto» (pág. 57), concluía así (pág. 59): «No hay Derecho natural, no hay más que Derecho positivo, pero esto no quiere decir que el Derecho quede reducido a algo casual y arbitrario, desprovisto de valor ético. Al contrario: el Derecho en su puro concepto formal, como regulación general y cierta de las relaciones humanas posee ya un valor absoluto por estar referido al postulado de la persona como ser moral, es decir, obrando bajo el imperativo de una ley absoluta en el mundo sensible» (...) «La última consecuencia de esta concepción es, por eso -añade aquél- que la existencia del Derecho como orden general y cierto de la convivencia es un postulado de la razón. En esta consecuencia -finaliza- se halla el tránsito de la teoría del Derecho a la teoría del Estado». Habría que indagar, pues, en qué medida es aquí kantiano Felipe González Vicén.

${ }^{13}$ Algún día habrá, al fin, que pasar a limpio -superando pereza y pudor- toda aquella documentación, todo aquel material, toda aquella basura que tengo encerrada -apenas ya en mis vivencias, como lejanos recuerdos y 
Volviendo de nuevo a la consideración de sus posiciones teóricas y metodológicas, hay que hacer observar asimismo como, en sintonía con tal trasfondo historicista, Legaz Lacambra en sus tiempos y Adela Cortina recientemente han apuntado también a la calificación, aunque referida a muy diferentes momentos, de tal actitud como existencialista $^{14}$. En ambos vinculables supuestos -historicismo y/o existencialismo-, aquél parece situarse en contraposición, mayor o menor, con una fundamentación kantiana que resultaría siempre más exigente en cuanto a la posibilidad y necesidad de la universalización de los juicios y los deberes éticos. No habría, sin embargo, que olvidar -con base en su ya aducida obra sobre la filosofía de Kant- que en alguna reciente ocasión y hablando precisamente de estos temas ${ }^{15} \mathrm{el}$

resquemores- en un viejo y grueso carpetón con papeles, notas, cartas, requerimientos, recursos y otras mil zarandajas impresentables de aquellos increíbles tiempos. Me digo que hay que hacerlo sobre todo por «objetividad histórica» -de la pequeña historia desde luego- de nuestro país y de nuestra Universidad en esos momento, años finales de los sesenta y principios de los setenta, y no digamos de antes: también para que los jóvenes sincrónicos de hoy, aunque no quieran y por su propio «bien», no olviden ni desconozcan del todo el pasado, su pasado, y asimismo porque de este modo tal vez puedan rescatarse todavía cosas de las que, en buena, mala, parte, como es bien sabido, no suelen quedar en determinadas circunstancias demasiados testimonios escritos ni mucho menos documentos oficiales. En su ya mencionado trabajo sobre la Filosofía del Derecho en España (1960-1985), Juan José Gil Cremades que también fue sujeto pasivo de algunas de esas arbitrariedades recuerda, en efecto, el muy destacado protagonismo que en aquellos tiempos exhibió el catedrático de Sevilla Francisco Elías de Tejada y Spinola quien -dice- «sin tener cargos políticos, salvo la presencia en el Consejo de Educación, tenía acceso, complaciente o no, a los despachos de quienes los tenían»; en nombre de la más rígida ortodoxia tradicionalista, católica y reaccionaria, se instauró así una incansable represión y persecución universitaria con muy negativas implicaciones, a veces, de carácter también político-social; «la verdad es que» -concluye sin exageración alguna Gil Cremades- «aquella situación creó un cierto terror intelectual» (págs. 232 y 233). Me parece que, recordando al profesor González Vicén, era ineludible y obligada esta referencia a situaciones y actuaciones contra las que él denodadamente luchó.

${ }^{14}$ Luis Legaz Lacambra, Situación presente de la Filosofía jurídica en España (1945), trabajo incluido en su libro Horizontes del pensamiento jurídico, Barcelona, Bosch, 1947, págs. 352-353: esa «posición existencialista, típicamente heideggeriana» que Legaz sitúa como anterior no le impide señalar, sin dar mayor explicación, que después -escribe- «este autor más bien parece considerarse representante de una especie de negohegelianismo». Sobre ello, de Adela Cortina, $L a$ calidad moral del principio ético de universalización, «Sistema», núm. 77, marzo de 1987, págs. 111-120 y, últimamente, Etica sin moral, Madrid, Tecnos, 1990, especialmente aquí, págs. 148-151.

${ }^{15}$ Entrevista con Felipe González Vicén, realizada por Manuel Atienza y Juan Ruiz Manero y publicada en «Doxa. Cuadernos de Filosofía del Derecho», 
profesor González Vicén declaraba explícitamente la exigencia de «un fundamento ético que de por sí sea vinculante para toda persona con un uso normal de razón».

Estos y otros importantes problemas a ellos conectados -y que hacen referencia al kantismo, hegelianismo, historicismo, existencialismo- son, como se ve, algunos de los que están planteados y quedan abiertos para ser cuidadosa y cronológicamente confrontados en su obra. Una obra, pienso, no exenta tampoco de ambigüedades, lagunas y hasta posibles contradicciones e inconsecuencias pero llevada siempre adelante por él con un gran esfuerzo y escrupulosa meticulosidad: siempre decía -recuerdo- que si una página estaba bien trabajada y bien escrita no se debería poder cambiar en ella ni una sola palabra, y yo creo que aspiraba a eso en todas sus obras, en toda su obra.

Pero -hay que decirlo- el intelectual pulcro, exigente, riguroso, muy crítico y autocrítico era también un gran vitalista, tanto en los hechos como, quizás sobre todo, en las palabras y en los signos; y era también un hombre dotado de un gran sentido del humor, en ocasiones necesariamente cáustico, siempre con una sutil ironía por medio (acompañada en todo momento por el famoso, temible, carraspeo). Yo le veía con frecuencia, desde hace mucho, cada vez que venía por Madrid: me contaba miles de cosas del pasado, sobre todo de la Alemania dual y escindida de los años veinte/treinta, y también del presente, a menudo dando entrada -justo es reconocerlo pero todos, y él, éramos conscientes- a su gran capacidad de fabulación; largas, larguísimas conversaciones, nocturnas por lo general, también discusiones a medida que yo fui tomando confianza, unas y otras concluidas en todo caso -era, a esas horas, el más resistente y eso que yo también aguanto lo mío- con discurso final suyo donde el distanciamiento escéptico y crítico nunca cegaba en él su profunda, hasta radical y siempre muy personal veta moral.

Le gustaba jugar con las situaciones y provocar reacciones y anécdotas que luego desgranaba con morosidad, inteligencia y buen humor. Le recuerdo, por ejemplo, en los primerísimos momentos de la transición creando, divertido, la confusión con su nombre y primer apellido cuando, tras Suresnes, el joven líder del renovado socialismo español comenzaba apenas a salir de la clandestinidad y a ser por muy pocos conocido en persona. Instalado nuestro filósofo, con su aire de gran señor, en la solemne rotonda y en el elegante bar del Hotel Palace, donde invariablemente

Universidad de Alicante, 1986, págs. 317-325 y aquí, en concreto. pag. 320. 
se alojaba en sus viajes a la capital, se hacía llamar de esa forma (como don Felipe González) de viva y alta voz, y repetidamente, por los encargados de recibir los mensajes o las llamadas telefónicas (¿era su hijo Fernando, muy simpatizante socialista, el cómplice de tal conspiración?): tras hacerse el sordo durante un buen rato, algo ya lo estaba de verdad, multiplicado el efecto difusor, se alzaba retador, dejándose observar. Me contaba después, enardecido, que con ello provocaba las iras hipócritas de muchos de los habituales del hotel -generales y ricachones, añadía- a los que según él (¡todo un precursor!) había que obligar y que ir acostumbrando a que vieran socialistas también por estos ambientes y lugares.

Pasado el tiempo, yo le rememoraba todo esto cuando el gran triunfo electoral del 28 de octubre de 1982 fue recibido por el PSOE instalando precisamente en dicho hotel su despacho y oficina central, todo el mundo por aquellos salones intentando ahora abrazar, o al menos tocar, al carismático secretario general: yo creo que él lo veía, con su pedagógica siembra, hasta como un triunfo personal. Desde el principio de la transición, aunque luego poco a poco fue haciéndose más crítico, me reafirmaba con aire de ancestral sabiduría: «Bueno, Felipe González (Vicén) le votó a usted (se refería a las, ya mencionadas y tan conflictivas oposiciones para la cátedra), así que en definitiva es lógico y es justo que sea ahora usted quien vote a Felipe González (Márquez) para la presidencia del gobierno; es lo menos que puede hacer. Y hablando así, de concordancias objetivas, de desenvolvimientos evolutivos, de grandes leyes de la historia, de sistemas que al final todo lo comprenden, incluso críticamente, él, ¿el no kantiano? se ponía otra vez también hegeliano...

Nos vimos y, sobre todo, nos hablamos con frecuencia en todo ese tiempo que lo fue también de colaboración. Siete importantes trabajos publicó González Vicén precisamente en Sistema, algunos asimismo en otras revistas, en esa década que va de 1978 a 1989, en la que trabajó muy duramente, consciente ya de su situación, para acabar de dar forma a investigaciones retenidas algunas desde tiempos anteriores y a otras nuevas o renovadas: uno sobre Ernst Bloch y el Derecho natural, tres -documentadísimos- sobre el joven Marx, incluido Feuerbach, otro sobre Lorenz von Stein y dos, más breves, finalmente, sobre el famoso tema y consiguiente debate de la obediencia y la desobediencia al Derecho, que entre nosotros fue él precisamente quien lo lanzó y después lo alentó ${ }^{16}$.

${ }^{16}$ Las referencias exactas de todos esos trabajos, títulos y fechas, pueden 
Sabía perfectamente que ya no tendría mucho tiempo y trataba por ello de aprovecharlo al máximo: sus graves dolencias, por lo demás. le retenían forzada pero gustosamente en La Laguna. Hubo un último intento de hacerle salir, y fue con ocasión del homenaje que los profesores españoles de filosofía jurídica, ética y política le hicimos en la ciudad de Elche dentro del marco de las Jornadas de trabajo organizadas por la Universidad de Alicante, en diciembre de 1987: le instamos cariñosa y hasta coactivamente pero ya no se encontró con fuerzas para asistir.

Sólo pude verle una vez más, en una inolvidable visita que, junto con Juan Ramón Capella, le hicimos en su casa de La Laguna en marzo de 1989: sentí -don Felipe ya muy enfermo- que aquella era nuestra despedida personal, salimos de allí cabizbajos, deprimidos, sumamente tristes al verle ya tan mal, tan agotado, tan diferente físicamente del González Vicén de los viejos y buenos tiempos. Pero, frente a eso, él se resistía y siguió resistiéndose hasta el final: con lo que podía, con su trabajo, con su razón, pues la cabeza le funcionaba perfectamente bien.

Recuerdo de ese día que, con grandes dificultades, empezó a revolver papeles para leernos, ilusionado, algunos párrafos del escrito que en esos momentos bicentenario de la revolución francesa- el ilustrado hispano alemán se traía entre manos. Era un estudio sobre el para mí desconocido Pierre Bayle, precursor entre otras cosas de la idea de tolerancia antes de Locke, y se notaba con toda claridad que González Vicén se estaba identificando fuertemente con él. No retuve para nada el párrafo que allí nos fue leyendo, apenas se le entendía y yo sólo estaba atento a sus gestos y a su voz, pero luego después repasando con calma el ensayo publicado ${ }^{17}$ he pensado que debió ser, o tendría que haber sido, aquel ya del final con el definitivo autorretrato

encontrarse en el Índice acumulativo de «Sistema», preparado con ocasión del número cien, monográfico y conmemorativo, de nuestra revista, correspondiente a enero de 1991: no creo -el número salió con algo de retraso- que don Felipe alcanzara va a recibirlo. En «Sistema» se publicaron asimismo las que fueron quizás sus últimas lineas: un breve pero en algunos momentos incisivo y significativo comentario al libro editado precisamente por Javier Muguerza (a quien tanto quería aquél) y por Roberto Rodríguez Aramayo sobre otra vez, precisamente Kant después de Kant. En el bicentenario de la «Crítica de la razón práctica»; no era más que una escueta recensión, pero don Felipe me llamaba casi todos los días - parecía un principiante- ansioso por saber cuándo aparecería ese numero 97 de «Sistema» (julio ya de 1990) en que aquélla, en efecto, habría de publicarse.

${ }^{17}$ Este trabajo suyo sobre Pierre Bayle y la ideología de la Revolución apareció en el «Anuario de Filosofía del Derecho». tomo VI, 1989, pág. 15-22: el texto a que en concreto hago aquí referencia está en la pág. 21 de él. 
en que se nos muestra -escribió González Vicén- «un Bayle totalmente desconocido. Es -señala aquél- el Bayle libertario. Nacido, crecido y desarrollado bajo la persecución religiosa, y bajo la mano de hierro de Luis XIV, Bayle se construye a sí mismo un mundo libre, un mundo en el que no existen ni la reacción ni la persecución. Este mundo no es el de todos -entonces, advierte aquél, sería Peter Bayle un revolucionario pero sí su mundo, un mundo creído y sostenido por su razón y únicamente por su razón. Bayle se dice a sí mismo en estos apuntes libertarlos que él puede leer todos los libros que quiera y además escribir otros en contra. Que él puede criticar toda la planificación del poder central y además que todo eso lo puede hacer consigo mismo, sin pretender -se concluye allí con un profundo acento, íntimamente personal- que los demás le sigan».

Yo creo que eso es lo que él quiso leernos aquel día: y creo también que aquí, en no pocos de estos rasgos de la resistencia y la rebelión ética individual, encontró siempre y al final constante autorreconocimiento e identificación nuestro viejo maestro y amigo que fue el profesor Felipe González Vicén. 